\title{
Balancing Skills to Optimize Fun in Interactive Board Games
}

\author{
Eva Kraaijenbrink, Frank van Gils, Quan Cheng, \\ Robert van Herk, and Elise van den Hoven \\ Eindhoven University of Technology, P.O. box 513, 5600 MB Eindhoven \\ e.v.d.hoven@tue.nl
}

\begin{abstract}
Playing games against people with a different skill level can be boring or frustrating, which decreases fun. A solution is to introduce specific rules that balance a game. In this paper we describe a study in which we used an electronic board game with tangible interaction to investigate whether balancing a game indeed increases fun experienced. We also investigate whether balancing skill levels implicitly (players are unaware) or explicitly (players are aware) has an influence on the fun experienced. We found that players who lost a game felt more successful in the balanced game compared to the unbalanced game. The balanced game also offered the players more fun experience than they expected beforehand. Finally, players preferred to play an explicitly balanced game because it increased the feeling of effort and challenge.
\end{abstract}

Keywords: Balancing skills, board games, tangible interaction, game balance, interaction design, fun experience, and social interaction.

\section{Introduction}

In this paper we present a study that focuses on the balancing of differences in players' skill levels in a game.

Fun in games is influenced by three factors: fantasy, challenge and curiosity [14]. Offering a suitable amount of challenge can be difficult when people with different skills play together. When no effort is needed to beat an opponent a game is boring. Conversely, when an opponent is too challenging a game is frustrating. Boredom or frustration decreases fun, because challenge is not optimal.

When players are kept away from states where the game is boring or frustrating they are guided through the so-called 'flow channel' (see Figure 1), first described by Csikszentmihalyi [5] and put into a gaming context by Koster [9]. Balancing a game can be done implicitly or explicitly. In an implicitly balanced game, the players are not aware of the balancing mechanism. In an explicitly balanced game, they are. We further distinguish statically balanced games (based on skill level before the game) and dynamically balanced games (based on performance during the game).

First, we studied whether balancing a game changes the fun experience people have during the game in comparison to an unbalanced version. Second, we explored whether people prefer implicitly or explicitly balanced games. It could be argued that making the difference in skill level explicit encourages the weaker player to improve 
his/her skills in order to participate at the same level. It might, however, also reduce the willingness of people to play because they do not want to be identified as the weaker player among other players. To answer these questions a digital tabletop game with tangible interaction, featuring a balancing mechanism, was developed. Because we used new technology, we were able to create a dynamically and implicitly balanced game: the game constantly assesses the player's skill levels and dynamically applies balancing rules. The players themselves remained unaware of this balancing mechanism until we told them it was in place.

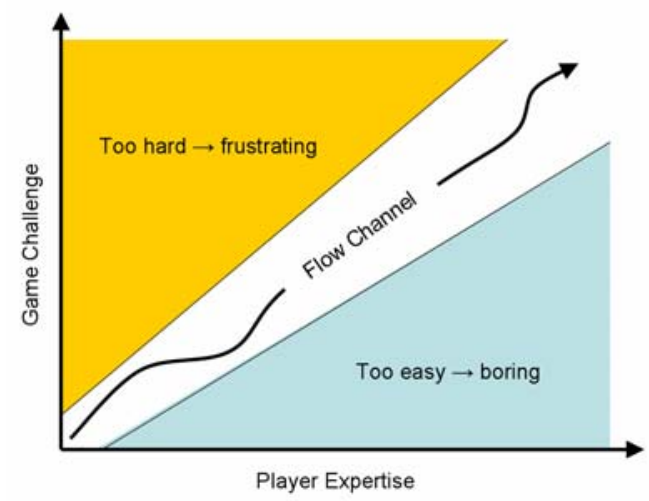

Fig. 1. The Flow Channel is the right balance between a challenge being too easy (leads to boredom) and too hard (leads to anxiety)

Balancing a game for players with different skill levels is not something new. The game 'Go', which originated in China more than 2500 years ago, already contained the possibility for two players with different expertise to play an equal match that is challenging for both. The balancing mechanism is explicit and static: the less experienced player is allowed to place one to nine stones already on the board at the start of the game, depending on the difference in expertise between the two players. Another well-known example of explicit static balancing is the 'handicap rule' in golf. Players that are less skilled clearly have a disadvantage, which is referred to as a 'handicap'. Their net score is calculated by subtracting the handicap from the gross score to be able to compare them to other players. Players that are less experienced can play against players that are more experienced and still have a challenging, competitive game.

An example of a balancing mechanism that is explicit and dynamic is the board game Wildlife [3]. In this game the player is helped by the rules of the game when falling behind during the game. It can be argued that the game is implicitly balanced because players can be unaware of the goal of the rules. The rules, however, are explicitly stated and explain the balancing mechanism.

Two examples of board games that use the possibilities of technology to create suitable challenges for players are a game called Tagtiles [34] that uses technology to offer children a challenge that is appropriate for their skill level and a tangible tabletop game that support therapy of children with cerebral palsy [35]. 
To set the right challenge in computer games, people can often adjust the difficulty before a game starts. Computer games typically offer different levels of difficulty (e.g., easy, normal and difficult) and adjust their challenge depending on the selection (explicitit static balancing). A new development is that the artificial intelligence of the game can analyze the expertise based on performance of the player and adjust the game implicitly [7][17] (implicit dynamic balancing). Research is also being done on the balancing of a game by recognizing emotions of a player [19]. The game is based on a number of emotion-data features like skin response, which are monitored continuously during the game (implicit dynamic balancing).

Combining traditional games and computer games give rise to interesting possibilities for mixing different ways to balance games. The expertise of a player of a tabletop game, for example, could be automatically assessed based on the placement of the game pieces on the game board before a game starts or during the game based on the amount of pieces that a player has lost.

\subsection{Pervasive Games}

There is a growing trend in today's games where the benefits of traditional games (physical movement and social interaction) and computer games (detailed graphics, animation and interactivity) are being combined [13]. This crossover is called pervasive gaming. To give insight in the various kinds of pervasive games some examples are described.

A first group of games is called computer augmented tabletop games that make use of a display as game board to create an interactive experience. Examples are 'KnightMage' on the STARS platform [12] and 'Weathergods' on the Entertaible platform [2]. These games use a display to show information and to create dynamically changing board configurations.

The second group consists of traditional boards that are augmented with electronics. Commercial examples of board games with very basic technology were already available in the seventies (e.g. Operation [3] and Electro [3]). Later examples are Vampire Hunter [3], where the game environment is completely changed based on the light that shines from a tower on the middle of the board and King Arthur [3] where the game board gives audio cues, tracks how you play and, adjusts the game accordingly.

Next to augmenting already existing traditional board games, such as the Settlers of Catan with an automatically changing board configuration and digital dice [4], games using advantages of technology are developed such as The MarbleGame that actually has an automatically and physically changing 'game board' [11]. Games that use the possibilities of technology to create challenges for players with different needs are called Tagtiles [21]. These games use technology to offer children a challenge that is appropriate for their skill level and a tangible tabletop game that support therapy of children with cerebral palsy [10].

Another group of pervasive games makes use of augmented reality. In these games the real world is combined with virtual reality. This makes it possible to play with tangibles, while using visually rich animations. An example is BattleBoard 3D [1], which uses physical flat markers that are recognized by a webcam, then 'translated' 
and shown as three-dimensional figures on a computer screen or via virtual reality goggles.

Finally, Head Up Games [16] such as Camelot [20] focus on social interaction, use interactive technologies but try to limit the use of displays. This is to create an interactive experience during which players keep there 'heads up'. A commercial product for Head Up games is Swinx [18]. Swinx is a game console focusing on active outdoor and indoor games. The base station gives feedback via lights and sound. Players can interact with the base station through bracelets containing RFIDtags. The base station can identify and track each individual player.

\section{User Requirements}

Before we could start with the design of the tangible board game we gathered user requirements that are defined based on an exploratory questionnaire.

\subsection{Questionnaire}

The questionnaire consisted of 4 parts: 1- Demographics: Gender, age and the frequency of play; 2- Best game features: The respondent could give 15 points, $(1,2$, 3, 4 and 5 points) to their favorite top 5 out of 12 game features; 3- Thoughts about skill balancing in games: The respondent had to specify his/her level of agreement on a 5-point Likert scale to 18 statements about the preferred opponent's skill level, help and hinder and implicit and explicit balancing experience during a board game; 4Added value of digital elements in board games: The respondent judged based on a 5point scale, the added value of 10 digital elements in board games.

\subsection{Results}

The age of the respondents $(n=53)$ ranged between 18 and 39 years, $42 \%$ females and $58 \%$ males. The respondents showed a wide variety in the frequency of playing computer and/or board games. There were three large groups that play 'once a week' $28 \%$ followed by 'less than once a month' (26\%) and 'once a month' $(23 \%)$. The minority plays 'once a day or more' (14\%) or 'never' $(9 \%)$.

First, the three preferred game elements out of 12 features were tactical insight (17\%), problem solving (14\%) and intelligence (12\%). Second, the respondents liked the idea that the game was balanced for differences in game expertise between opponents, because they preferred a suitable challenge for both players during the game. Respondents indicated that they prefer balancing methods that help the weaker player (e.g., by giving him/her clues) instead of those that hinder the stronger player (e.g., giving him obstacles on the board). Third, helping the weaker player should be done implicitly instead of explicitly, because respondents indicated that they do not like to be explicitly identified as the weaker player. Players did not want to receive help at the very last moment because that would obviously show that they were losing. Visual feedback from the board and the playing pieces was perceived as an added value to traditional board games.

Based on these findings the following user requirements were defined: 1- The game should include at least one of the following game elements: tactical insight, 
problem solving or intelligence; 2- Weaker players are implicitly helped throughout the game; 3 - The game board and playing pieces should give visual feedback.

\section{Concept}

Based on the defined user requirements two concepts were developed and made into paper prototypes. Seven pairs of people played both concepts. Afterwards people filled out a questionnaire about each concept and the winning concept was developed into the final concept.

Last Blood (see Figure 2) is the first paper prototype which is similar to the famous board game called Stratego [3], but augmented with technology. The pieces are set up on the four rows nearest to each player, one piece at a square with the backs of the pieces facing the opponent. The two central rows (with the small lake and wood) stay empty; the players are not allowed to deploy any pieces here. On the playing pieces an illustration of a number is shown that depicts the value of the rank (see Figure 2). The piece with five dots is the highest rank, the piece with one dot is the lowest rank and the bomb has no number, because it has a special role. Setting up is an important part of the game; victory or defeat can depend on it. In turns, players are allowed to move one piece one or two squares. Players can hit pieces of the opponent, resulting in a so-called battle. The piece with the highest rank wins a battle. Pieces die together when they have the same rank or if either piece is the bomb. After a battle is played, the losing player has to remove the playing piece from the game board. The players have won when s/he enters the red base of the opponent with one of his/her remaining pieces. Game rules are added that balance the game dynamically and implicitly: every time a player looses a piece, a 'bonus' appears near another game piece of that player. The players can collect these bonuses by stepping on it with a game piece. Players can use the collected bonuses in battles to raise the strength of a piece by one rank. If more bonuses are collected the strength of a piece can also be raised during a battle by two ranks. Since bonuses pop up near game pieces of players that loose battles, it is easier for loosing players to collect them, and hence the game is balanced. An additional feature that technology allowed us to implement is that, contrary to Stratego, players do not have to show pieces that are involved in battles to each other in order to decide which piece won. Using an electronic game board it is possible to automatically indicate which piece wins in order to keep its exact level hidden and the tactics a mystery.

Pyromaniac (see Figure 2) is the second paper prototype that was developed. The game is based on tactical insight and problem solving. The goal of the game is to arrest a pyromaniac who is on the loose in the forest. The electronic board controls the pyromaniac. The pyromaniac is not visible and hides 'inside' the board. Players have to make use of a police man playing piece to find and arrest the pyromaniac and firemen playing pieces to extinguish any fires the pyromaniac lights. The game is dynamically and implicitly balanced by the artificial intelligence of the pyromaniac.

The two games were played by 14 people to test the concepts. A questionnaire was filled out about the amount of fun and excitement they experienced within each concept. The players also had to give a grade and indicate which concept they liked 

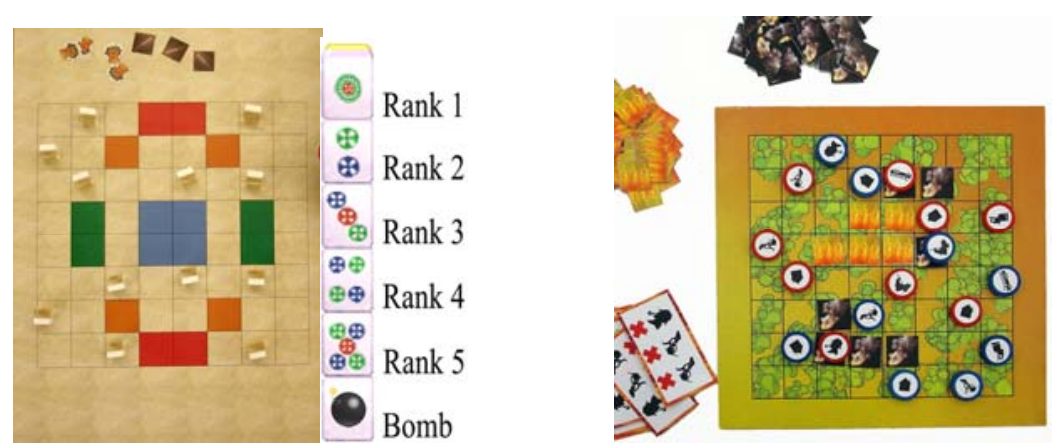

Fig. 2. Last Blood (left) and Pyromaniac (right) paper prototypes

the most. The preference for each concept was equally divided: 7 players ( 3 male, 4 female) chose Last Blood as their most favourite game and 7 payers (5 male, 2 female) chose for Pyromaniac. The average grade was a 7.1 on a 10-point scale for both concepts. Players pointed out that the amount of fun was the same for both concepts, but $64 \%$ of the players experienced more excitement during Last Blood. This result can be explained by the nature of both games. With Last Blood your opponent is the 'enemy' and therefore a competitive game. With Pyromaniac you try to find the same 'enemy', which makes it a collaborative game and hence moves of the opponent are of lesser importance. In addition, the rules of Last Blood were easier to understand and the duration of the game was shorter. Based on these findings Last Blood was chosen as a basis for the final concepts.

\section{Final Concept Last Ice}

A working prototype, with a new theme (see Figure 3) was built on the Edutainment Sensor Platform (ESP). This is a platform that is developed by Philips Research [6]. It can receive a variety of inputs (e.g., motion sensing, proximity detection and 2D object localization). On the basis of these inputs, it can then trigger a variety of outputs (including audio, LED arrays and amBX [15]). Applications for ESP are created with the ESPranto SDK, which is tailored towards allowing non-technical domain experts (e.g. game designers) to create their own content with little or no help from a software engineer [6].

The basic rules of the game Last Blood were implemented. Two versions of the game were programmed, namely the balanced and unbalanced game. In the balanced game a bonus was placed on the board near a piece that is on the side of the player that just lost a piece. In this way the game is assisting the weaker player by giving them extra points. The players will not change their strategy because they are unaware of this balancing mechanism. In the unbalanced game the bonus was randomly placed over the board. The board can decide who wins a battle and detect whether a player used a bonus. The board lights up where pieces are placed and indicates whose turn it is.

The game board was designed and printed on thick paper and put on top of the electronic board. The icebergs, shelters and bases were made of white wax to create 
an 'icy' look and were placed on top of the game board. The game pieces itself were made of Perspex. This material was chosen because of its transparency: colored light indicating which player owns which piece shines through the pieces. Coils were put inside the objects so that the 2D location detection electronics can track the pieces on the gaming board. Holes were drilled into the Perspex to fit the coils and pieces of paper handkerchiefs were used inside the hole to prevent the coils from moving. The hole was closed with transparent tape. Images of animals, which show the different ranks and weapons in the game, were attached to the Perspex game pieces with transparent tape (see figure 3).

Originally, we wanted to allow players to apply their collected bonuses and upgrade their pieces by physically shaking weapon pieces to create a feeling of 'powering-up'. The shake detection device used a wireless communication module using a specified radio frequency. However, the prototype shake detection device reached an accuracy of only $80 \%$ due to the quality of the radio transmission. Therefore, we decided not to use the shake detection in our user evaluation. Instead, players activated bonuses by placing a weapon piece on their own base within three seconds before a battle starts.
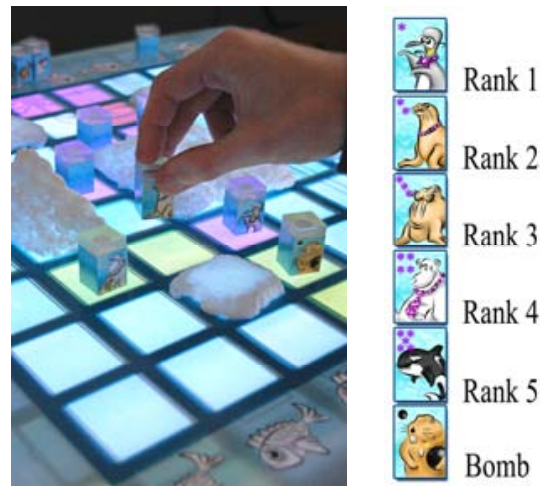

\section{Theme}

Due to the serious problem of global warming, the ice on the Arctic is melting fast. The animals living there have to fight for the last ice to live on. In order to survive, they have to put aside their differences and unite and infiltrate the base of a rivaling group of animals.

Fig. 3. Working prototype of the Last Ice concept and its tangible play pieces

\section{Experiment}

Based on the results of the first exploratory questionnaire, where the majority of the respondents indicated to prefer an equal challenge and that the weaker player was implicitly helped, the following hypotheses were tested:

Hypothesis 1: If the game is balanced then players will experience more fun compared to when the game is not balanced.

Hypothesis 2: If the game is implicitly balanced then players will experience more fun compared to an explicitly balanced game. 
The procedure and timing of the experiment was checked with a pilot experiment done with four participants. As a result of this pilot experiment, programming was improved and rules of the game were printed on paper.

The improved experiment was performed with a group of 40 participants (29 males, 11 females) with ages ranging from 22 to 40 . There were 16 frequent game players (12 male, 4 female) who played more than once a week, 14 participants (11 male, 3 female) were non-frequent game players, playing less than once a month. Seven participants played about once a month (5 male, 2 female) and three participants (1 male and 2 female) never played board games. We asked the participants about their experience in strategy games which require strategic thinking and planning. We decided to call players 'familiar' with strategic games when they played them at least 15 times. We found that $58 \%$ of the players were familiar with these games. A minority of $15 \%$ never played strategy games. In the experiment, each participant played the game twice against the same participant. Board games are most often played against a friend. We wanted to resemble reality and picked pairs that were familiar to one another. However, the ideal situation would suggest pairs where one player was much more skilled, but this was logically not feasible.

After filling in the pre-questionnaire and reading the rules, the game was practiced and explained by the experimenter. Half of the participants started with the unbalanced game and continued with the balanced game, the other half vice versa. After each game was finished a questionnaire was filled out. At the end of the two games the participants were told that they played a balanced and an unbalanced game. We asked them to give their opinion on implicitly and explicitly balancing a game and a post questionnaire was handed out. The experimental steps are described in Table 1 with an averaged time span.

Table 1. Experimental steps for the group, which started with the unbalanced game and continued with the balanced game

\begin{tabular}{ll}
\hline Time & Explanation \\
\hline $00.00 \mathrm{~h}$ & $\begin{array}{l}\text { The participant fills out a pre-questionnaire for demographic information and } \\
\text { questions regarding previous experience in games and expectations. }\end{array}$ \\
\hline $00.03 \mathrm{~h}$ & The participant reads the rules of the game. \\
\hline $00.06 \mathrm{~h}$ & $\begin{array}{l}\text { The participant starts practicing the unbalanced version of the game and the } \\
\text { experimenter gives instructions. }\end{array}$ \\
\hline $00.10 \mathrm{~h}$ & The participant starts playing the unbalanced version of the game. \\
\hline $00.18 \mathrm{~h}$ & $\begin{array}{l}\text { The participant fills out a questionnaire I, with questions regarding the fun } \\
\text { experience during the game. }\end{array}$ \\
\hline $00.21 \mathrm{~h}$ & $\begin{array}{l}\text { The participant starts with the balanced version of the game. } \\
00.29 \mathrm{~h}\end{array}$ \\
$\begin{array}{l}\text { The participant fills out a questionnaire II, with questions regarding the } \\
\text { experienced fun during the game and their preference for game } 1 \text { or } 2 .\end{array}$ \\
\hline $00.32 \mathrm{~h}$ & $\begin{array}{l}\text { The participant is interviewed about the notability of a balanced and unbalanced } \\
\text { game, about his/her preference regarding the two different games and his/her } \\
\text { opinion about implicitly and explicitly balancing a game. }\end{array}$ \\
\hline $00.36 \mathrm{~h}$ & $\begin{array}{l}\text { The participant fills out a post-questionnaire regarding the experienced fun now } \\
\text { s/he knows the second game was balanced for expertise. }\end{array}$ \\
\hline $00.40 \mathrm{~h}$ & \begin{tabular}{l} 
End of the experiment \\
\hline
\end{tabular}
\end{tabular}


The validated Game Experience Questionnaire (GEQ) [8] was used to measure the fun experienced during the balanced and unbalanced game. The questionnaire consisted of 22 questions. A typical question would be: 'I felt successful' and the participant could indicate how s/he felt during the game with the use of a 5 point Likert scale ranging from 1 (Totally disagree) to 5 (Totally agree). The players were also asked to indicate their fun experienced after each game and in which game, the first or second, they experienced more fun and competition.

In the interview, open questions were asked about the players' opinion about implicit or explicit balancing of games. The post-questionnaire consisted out of 11 questions of the GEQ questionnaire to investigate whether the fun experienced changed after the participant knew one game was balanced. An example question was: 'Now I know that I played a balanced game my experienced fun..' which participant's had to complete on a 5 point scale ranging from 1 (..decreased al lot) to 5 (..increased a lot). During the experiment the concrete differences between the two games (amount of pieces left, collected and used bonuses, and playtime) were also recorded.

\section{Results}

\subsection{Difference between the Balanced and Unbalanced Game}

The results of the individual questions of the Game Experience Questionnaire shows that there was a significant difference in feeling successful between the balanced and unbalanced game as tested by paired sample t-test on a 0.05 level $(-2.7 ; 39,0.01)$. This means that players felt more successful during the balanced game $(\mathrm{M}=3.8$, $\mathrm{SD}=0.92)$ compared to the unbalanced game $(\mathrm{M}=3.3, \mathrm{SD}=1.13)$. If we look closer (see figure 4), we see that the player that lost felt more successful during a balanced game compared to the unbalanced game as tested with the one way Anova-test on a 0.05 level $(14.8 ; 38,0.00)$. In contrary, the winner felt equally successful during the two games (one way Anova 0.03; 40, 0.86). In general, winners felt more successful than the players that lost a game as tested with the one way Anova (balanced 11.4; 39, 0.00 , unbalanced $72 ; 39,0.00$ ).

Before the players started to play $83 \%$ expected to have more fun than average $(\mathrm{M}=3.98, \mathrm{SD}=0.73)$. After they have played the balanced game the amount of fun based on the question 'I had fun during this game' significantly increased to $93 \%$ (balanced $\mathrm{M}=4.27, \mathrm{SD}=0.60$ ) as tested by the paired samples t-test on a 0.05 level $(5.2 ; 38,0.004)$. In the unbalanced game the fun experience increased slightly to $85 \%$, which was insignificant $(\mathrm{M}=4.22, \mathrm{SD}=0.77)$. This means that the fun experience during the balanced game was more than the players expected it to be beforehand, while the fun experience in the unbalanced game remained the same.

During the interview $75 \%$ of the players preferred a balanced game because they expect it would give them more competition, challenge and excitement compared to a unbalanced game. However, many of the players (66\% from the $75 \%$ that preferred a balanced game) commented that they would like to decide themselves which type of game to play, because this depends on the skills of the opponent. When they play 


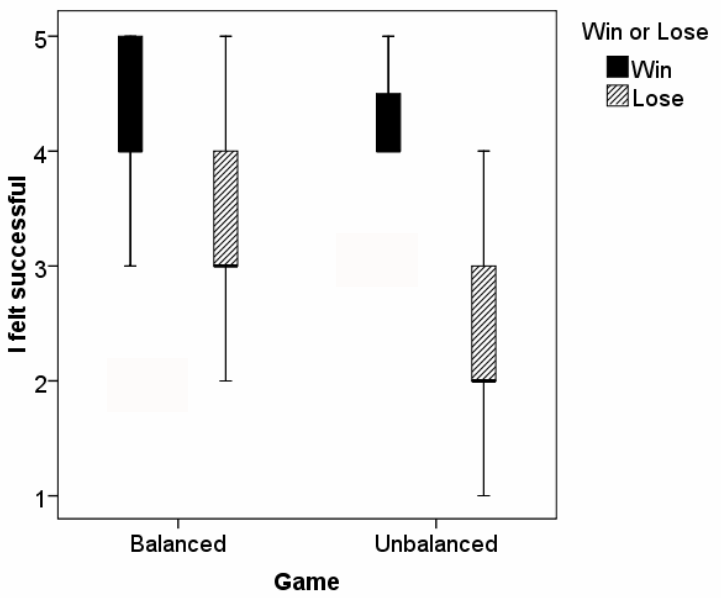

Fig. 4. The feeling of success after winning and losing a balanced and unbalanced game

against a child or an inexperienced player, they would choose a balanced game, but when they play against an opponent with the same game experience they would choose for an unbalanced game.

There were no differences between the total amount of play pieces that remained on the board after the game had ended $(1.32,39,0.20)$, also the collected bonuses $(-1.15,39,0.26)$, the used bonuses $(-1.1,39,0.28)$ and the playing time $(1.48,37$, $0.15)$ between the unbalanced and balanced game were the same.

Except for the question about feeling successful in the Game Experience Questionnaire, the difference in fun experienced during the balanced and unbalanced game of all questions in the GEQ were not significant as tested with a paired sample t-test on a 0.05 level. Thus the players experienced the same amount of fun in both games. The first hypothesis, that players experienced more fun when the game is balanced compared to when the game is not balanced, was therefore rejected.

The gaming skills of a participant (based on self-proclaimed experience in the prequestionnaire) does not significantly influence the amount of fun experienced during the balanced or unbalanced game as measured with a one way Anova-test on a 0.05 level (balanced $0.23 ; 35,0.93$, unbalanced $0.92 ; 35,0.46$ ). This means that players with more gaming expertise experienced the same amount of fun during the games.

\subsection{Implicit and Explicit Balancing of Expertise}

In the interview the players were told one game was balanced and almost all players $(95 \%)$ did not notice it. Players were asked in the post-questionnaire to indicate if the experienced fun changed now they were aware that a game was balanced. Explicitly balancing the game led to a significantly increase in the experienced amount of effort $(2.08,39,0.04)$ and amount of challenge $(2.69,39,0.01)$. This indicates that when players know that the game was being balanced based on their skill levels it will increase their experienced effort and challenge. The second hypothesis that players experience more fun when the game is balanced implicitly compared to explicitly was 
therefore rejected; players experienced more fun in the explicitly instead of implicitly balanced game.

Balancing a game could be kept secret, but many players think it would be unfair if they discover after many games that the weaker player was helped. Therefore, most players $(82 \%)$ did not prefer implicit balancing and suggested balancing a game explicitly.

\section{Discussion}

The study presented in this paper raised some points for discussion. Sometimes the game had to be restarted due to errors. As a consequence the collected bonuses were lost, but the game could continue where the players had left off. This happened in 10 of the 40 games, but in only four games collected bonuses were lost (in the other games the participants did not have bonuses at that moment). This did not influence their games, because the four errors occurred in the beginning of the game when only one battle was played and the difference in play pieces was still small.

Players told that they prefer explicitly balanced games: they would like to know when the game is being balanced. However, if we would have made explicit that our game has a balancing mechanism, the stronger player actually could adjust his tactics (lose weak game pieces in order to use bonuses on the stronger game pieces) and abuse the balancing mechanics (i.e. bonuses are meant for the weaker player).

The balancing mechanism of the game was unfortunately not always effective enough. This was especially apparent when players with a big difference in expertise would play against each other. While the bonus appeared near the player that just lost a piece, it might be that this player still had more pieces than the other player and actually should not get help. Also the importance of the piece that was just lost was not taken into account by the balancing mechanism. Balancing the game would have been more effective if these two aspects also would have been considered.

We observed a learning effect considering the comprehensibility of the game. When the game was played for the second time, players appeared more conscious about their own tactics and experienced more competition because they became more absorbed in the game. Nevertheless, a learning effect was counterbalanced because half of the participants started with the balanced game and the other half with the unbalanced game to control for order effects. However, the players could have practiced the game more often, because after the second game the players indicated that they would change their tactics if they played again. This does not influence our results because all the players did not play this game before and had to find out which tactics they wanted to use.

The results of the GEQ questionnaire showed that players that lost a game, experienced more success in the balanced game compared to the unbalanced game. Although the feeling of success would suggest that it was influenced by the amount of play pieces that remained on the board after the game had ended, and the collected and used bonuses, there was no significant difference for these factors between these two conditions. This would imply that the feeling of success is influenced by something else besides the variables that were measured in this study. For future study it would be interesting to investigate which factors in a balanced game are 
responsible for feeling successful. Games should have the possibility to balance because it decreases differences in skill and brings diverse players closer together.

\section{Conclusion}

In this study it was investigated whether players experienced more fun when the game was balanced compared to when the game was not balanced. Also whether people preferred an implicitly or explicitly balanced game was examined.

The results of the GEQ questionnaire revealed that players that lost a game felt more successful during the balanced game compared to the unbalanced game, while the feeling of success for the players who won remained the same. The balanced game also elicits more fun experience than the players expected to have beforehand, while in the unbalanced game the fun experience was as they expected it to be.

During the interview players indicated that they preferred a balanced over an unbalanced game. They thought a balanced game would give more competition, challenge and excitement compared to an unbalanced game. However, players would like to have an option which game they want to play depending on the skills of the opponent.

According to the results of the Game Experience Questionnaire no difference was found between the unbalanced and balanced game in terms of the experienced fun during the games. Also the experienced fun of players with different gaming skills was the same for the balanced and unbalanced games, so regardless whether the weaker player was helped or not.

The players experienced more effort and challenge when they knew beforehand that the game was balanced (explicit balancing). The players preferred an explicitly over an implicitly balanced game. They believed it would be better when all players knew the weaker player was helped instead of keeping it secret (implicitly balancing). It was very important that balancing rules do not make a game feel completely random, because this would leave skillful players feeling cheated, while weak players would not feel the drive to learn. It was also important to construct balancing mechanics in such a way that players are not able to abuse them. This would defy the purpose of the balancing and make it an even more unbalanced game.

Through the use of technology we can create dynamically balanced games that reduce differences in skills between players and are proven to have a positive impact on the feeling of success. Balancing also offers players more fun than they expected beforehand and finally brings players of diverse abilities closer together.

\section{References}

1. Andersen, T.L., Kristensen, S., Nielsen, B.W., Grønbæk, K.: Designing an Augmented Reality Board Game with Children: The BattleBoard 3D Experience. In: Proceedings of OZCHI, pp. 22-24 (2004)

2. Bakker, S., Vorstenbosch, D., van den Hoven, E., Hollemans, G., Bergman, T.: Weathergods: tangible interaction in a digital tabletop game. In: Proceedings of Tangible and Embedded Interaction Conference, pp. 151-152 (2007) 
3. BoardGameGeek, http://www.boardgamegeek.com (last accessed on December 2008)

4. de Boer, C.J., Lamers, M.H.: Electronic augmentation of traditional board games. In: Rauterberg, M. (ed.) ICEC 2004. LNCS, vol. 3166, pp. 441-444. Springer, Heidelberg (2004)

5. Csikszentmihalyi, M.: Flow: The Psychology of Optimal Experience. Harper and Row, New York (1990)

6. Herk, R., van Verhaegh, J., Fontijn, W.: ESPranto SDK: An adaptive programming environment for tangible applications. In: To be published in CHI 2009, proceedings. ACM, New York (2009)

7. Hunicke, R., Chapman, V.: AI for dynamic difficulty adjustment in games. In: Challenges in Game Artificial Intelligence AAAI Workshop, pp. 91-96 (2004)

8. IJsselsteijn, W.A., de Kort, Y.A.W., Poels, K.: The Game Experience Questionnaire, GEQ (2008)

9. Koster, R.: Theory of Fun for Game Design. Paraglyph Press, Phoenix (2004)

10. Li, Y., Fontijn, W., Markopoulos, P.: A tangible tabletop game supporting therapy of children with cerebral palsy. In: Markopoulos, P., de Ruyter, B., IJsselsteijn, W.A., Rowland, D. (eds.) Fun and Games 2008. LNCS, vol. 5294, pp. 182-193. Springer, Heidelberg (2008)

11. Lundgren, S.: Joining Bits and Pieces - How to Make Entirely New Board Games Using Embedded Computer Technology. Computing Science, IT (2002)

12. Magerkurth, C., Memisoglu, M., Engelke, T., Streitz, N.: Towards the next generation of tabletop gaming experiences. ACM Proceedings of Graphics Interface 62, 73-80 (2004)

13. Magerkurth, C.: Pervasive Games: Bringing Computer Entertainment Back to the Real World. ACM Computers in Entertainment 3(3), 11-29 (2005)

14. Malone, T.W.: Toward a theory of intrinsically motivating instructions. Cognitive Science 4(13), 333-369 (1981)

15. Philips Research Technology Backgrounder - Tangible Interaction Console, http: / /www.research.philips.com/newscenter/archive/2007/ backgrounders/070830-tagtiles.html (last accessed on December 2008)

16. Soute, I.: HUGs: head-up games. In: Proceedings of Interaction Design and Children conference, pp. 205-208 (2007)

17. Spronck, P., Sprinkhuizen-Kuyper, I., Postma, E.: Difficulty Scaling of Game AI. In: Proceedings of Intelligent Games and Simulation Conference, pp. 33-37 (2004)

18. Swinx, BV: Swinx. Swinx Information Leaflet, http: / /www. Swinxs. com/en/cmsmadesimple/uploads / (last accessed on December 2008)

19. Tijs, T.J.W., Brokken, D., IJsselsteijn, W.A.: Dynamic game balancing by recognizing affect. In: Markopoulos, P., de Ruyter, B., IJsselsteijn, W.A., Rowland, D. (eds.) Fun and Games 2008. LNCS, vol. 5294, pp. 88-93. Springer, Heidelberg (2008)

20. Verhaegh, J., Soute, I., Kessels, A., Markopoulos, P.: On the design of Camelot, an outdoor game for children. In: Proceedings of Interaction Design and Children Conference, pp. 9-16 (2006)

21. Verhaegh, J., Fontijn, W., Hoonhout, J.: TagTiles: optimal challenge in educational electronics. In: Proceedings Tangible and Embedded Interaction Conference, pp. 187-190. ACM, New York (2007) 